\title{
Error Analysis in the Use and Realization of Inflectional Morphemes among EFL University Students
}

\author{
Ismael F. Hussein ${ }^{1}$, Amina Mohammad Basil ${ }^{2}$ \\ College of Education For Humanities, Mosul University, Iraq
}

\begin{abstract}
This study aims to identify, describe and analyze errors committed in the area of inflectional morphemes by the 3rd year EFL students at the College of Education for humanities, Department of English/ College of Education for Humanities/ University of Mosul, during the academic year 2016-2017,. In order to identify the areas of difficulty and find out what makes these areas difficult, errors are classified with reference to the eight types of inflectional morphemes. To that end, Error Analysis Theory; notably, a fused version of the guidelines offered by Corder (1973) and Ellis (2005), is adopted. The mechanism of applying this version of error analysis on the data collected passes through various analytical stages, starting with data collection, identification of the areas of difficulty, description, explanation, and ending with the evaluation of errors. The present study was conducted to find out students' errors in using inflectional morphemes that include : past tense inflection "ed1", plural inflection "s", present participle inflection "ing", third person singular "s", past participle "ed2", possessive inflection " 's ",comparative "er" and superlative inflection "est". The aim of this study is to find out the errors made by students in using inflectional morphemes, and most importantly, the type of such errors ; whether they are,errors of omission, addition, misinformation, misordering, or those of blending. The subjects of this study were 100 EFL students in third -year at the university of Mosul. The results of the analysis show that the total number of errors found in the students' essays is 864.The objective outcome of the analysis conducted reveals a number of findings and conclusions; among these are, the percentage of "ed1" morpheme errors comprised 35\% of the total types of errors, the second rank is the plural morpheme " $\mathrm{s}$ " errors $=17 \%$, the "ing" morpheme errors $=14 \%$, the third person singular " $\mathrm{s}$ " $=13 \%$,"ed 2 " errors $=12 \%$, possessive morpheme errors $=7 \%$, Finally the comparative "er" and the superlative "est" comprised the lowest rank of percentage ;that is $1 \%$. Based on the findings of this research, it is hoped that it would help other researchers to build up further discussions and researches on errors with broader aspects and different subjects.
\end{abstract}

KEYWORDS : English Morphemes, Free Morphemes, Bound Morphemes, Inflecional Morphemes,

Derivational Morphemes.

\section{INTRODUCTION}

In Iraqi universities, English is taught as a foreign language, and the developing of the students' writing performance is one of its teaching courses, and the students are required to think critically and write correctly. At the University of Mosul, there are four departments of English with a large number of English Foreign Language (henceforth, EFL) students and teachers who have been facing a big challenge of errors raised from the target language performance; notably, writing activities. As it is widely known and usually diagnosed by the teachers in our university, there are

Academic Journal of Nawroz University

(AJNU) Volume 7, No 3 (2018).

Received 10 April 2018;

Regular research paper : Published 20 July 2018

Corresponding author's e-mail : ismael.husein@yahoo.com

Copyright (02018 Ismael F. Hussein, Amina Mohammad Basil.

This is an open access article distributed under the

Creative Commons Attribution License. some common, often frequent, errors shared by the majority of the students. Some students make errors when they deal with the third person singular, or with plural. Most frequent errors are also observed in areas like; the addition of the "ed1" morpheme and present participle morpheme, etc. These errors with their morph syntactic consequences are, in fact, the product of the defective use of the Inflectional Morphemes (henceforth, IMs) in writing. Because of their grammatical functions, IMs, the smallest linguistic units, are, thus, problematic when they are used incorrectly, partic ularly for students involved in reading. The students are often confused when errors occur in writing, and hence, they might fail to understand the intended meaning of the writer (student). It is this motivation that sets out the idea behind the presentation of the present study. The study is concerned with the identification of the problems that face EFL students in their use of IMs in terms of the types and the frequency of errors. Errors are identified, 
described and analyzed in the light of the theory of Error Analysis (henceforth, EA). This is to be done with the viewpoint that errors might not be seen as signs of failure. Rather, they are seen as the clearest evidence of the need for developing the systems of learning and teaching. Going in harmony with this view, the orientation of the present study, therefore, is based on the principles and procedures of the general EA theory, and on those of Corder's (1973) and Ellis's (2005), in particular.

\subsection{The Problem}

The major problem that the study tries to deal with is that most EFL university students make errors in using IMs. In the course of learning English as a foreign language many students are unable to use the IMs correctly in their writing. Examples of such errors are students' addition of the plural " $\mathrm{s}$ " inflection to a noun which has irregular plural "child", which is pluralized by the students of the selected sample as *"child". Furthermore, most of the students have double marked nouns or verbs e.g. ${ }^{*}$ "children" is double marked for plural and in "He did not left his friends" the verb phrase is double marked for past tense. So, the study strongly focuses on the need to find out the types and frequency of errors in using IMs which are reflected in students' poor and ineffective writing.

\subsection{The Aims}

This study aims to :

1.Investigate the errors in inflectional morphemes EFL University students make in their writings, identify their types, describe, explain and show their percentages of occurrence.

2. Attract the attention of the students to the importance and usage of IMs in their writings, since they occupy an essential part in dealing with grammar.

3.Suggest some sound remedial techniques to minimize EFL university students' errors in using IMs.

4. Find out the reasons why the EFL students make errors in their writing.

\subsection{The Hypotheses}

The study poses the following hypotheses:

1.EFL university students commit many errors in their use of IMs as they are involved in writing activities.

2. Most of the students in the Department of English Language at the College of Education for Humanities/ University of Mosul, do not know how to use the IMs.

3. Many students are unable to differentiate between some of the IMs like regular and irregular plural. They overgeneralize the rules of regular plural to include all nouns, and they use (ed1) morpheme to make irregular verbs in the past form.

\section{Theoretical Background}

In this section, focus will be on two major topics that form the backbone of the study; Error Analysis and IMs.

\subsection{Error Analysis}

Learning EFL, like any other learning process, involves making errors, i.e. it is difficult to learn a language perfectly within a few weeks or months. It may take years to master it. In other words, English language is full of irregularities which hinder the process of learning, and hence, learners commit errors in writing as well as in speaking. For many years, there have been studies about errors made by native speakers of English and the learners of EFL have taken place.Error analysis (henceforth, EA) is one of these studies that answer some questions concerning making errors. This study enables teachers to find out the sources of errors and take pedagogical procedures towards them. There have been many attempts and scholars have come up with different definitions of EA.Basically those definitions contain the same meaning while the difference lies only in the ways they formulate them. EA theory is firstly conducted by the well-known linguist Stephen Pit Corder who is regarded the godfather of this method and defines EA as systematically analyzing errors made by language learners makes it possible to determine areas that need reinforcement in teaching (Corder, 1974). Abisamra (2003:7) comments on the concept of EA as a type of linguistic analysis which focuses on the errors learners make. Crystal $(2008: 173)$ regards EA as a technique used effectively in language teaching and defines it as "a procedure for identifying, classifying, and systematically interpreting the unacceptable forms produced by someone learning a foreign language, using any of the principles and procedures provided by linguistics". Another definition is given by Dulay (1982) in his book (language).EA is defined as the process of language learning involves the making of errors. Errors are the flawed side of learners' speech or writing. EA is described as "a set of procedures for identifying, describing and explaining learners' errors" (Ellis and Barkhuizen, 2005 : 51). To conclude, on the basis of what already been discussed, the most convincing definition that is adopted in this research is the one given by Corder (1974)which refers to the steps which must be followed in conducting an EA research.

\subsection{Errors vs. Mistakes}

This study was conducted within the theoretical framework of Corder's explanation (1974) of errors and mistakes. According to him, errors occur because of gaps in the learner's L2 knowledge, whereas mistakes occur when the learner has not yet learned how to master a certain grammatical form (Ellis \&Barkhuizen, $2005: 62$ ). The distinction between errors and mistakes is not easily made in the analysis of data. In order to analyze learners' errors in a proper perspective, it is strictly necessary to go over the definitions of the two different phenomena, i.e. errors and mistakes. According to Keshavarz (2003), a mistake is made by 
the learner while he is speaking or writing because of lack of knowledge, attention, carelessness, slips of the tongue or pen, false starts, or some other aspects of performance. Mistakes are random deviations, unrelated to any system. Mistakes can be self-corrected when attention is drawn. Whereas, Errors are rulegoverned and systematic in nature and as such indicative of the learner's linguistic system at a given stage of language learning (ibid : 49). Brown (2000 : 257) emphasizes that a mistake refers to a performance error in that the learner fails to utilize a known system correctly, while an error is a noticeable deviation from the correct rules of a native speaker, which reflects the interlanguage competence of the learner. Errors reveal something about the learner's underlying knowledge of the target language. They are attributed to linguistic and non-linguistic factors (Keshavarz, 1999 : 49-50). Mistakes, on the other hand, are random and can be corrected by the learner if his attention is called to them. They may be attributed to non-linguistic factors, such as fatigue, strong emotion, lack of concentration, memory limitations (ibid : 51-2).

\subsection{Models of Error Analysis}

The Model adopted in the current research is an eclectic one putting together the models suggested by Corder (1973) and Ellis (2005; elaborations on Corder's model). Accordingly, the stages to analyze errors are as follows : 1. Data collection : Recognition of idiosyncrasy, i.e. first, the analyst should differentiate between an error and a mistake. Then, he should compare the erroneous sentence with a reconstructed sentence, which is, what a native speaker of the target language would have said to express meaning in that context, i.e. it is a translation equivalent.

2. Description : Accounting for idiosyncratic dialect. In other words, the two languages, i.e. the learner's language and the target language, are described in terms of a common set of categories and relations. That is, in terms of the same formal model.

3. Explanation (the ultimate object of error analysis),i.e. in this stage, attempts are made to account for how and why the learner is committing errors.The preceding suggested stages are narrowed down to the following steps :

1. Collection of data (either from a 'free' composition by students on a given theme or from examination answers).

2. Identification of errors (labeling with varying degree of precision depending on the linguistic sophistication brought to bear upon the task, with respect to the exact nature of the deviation, e.g. dangling preposition, anomalous sequence of tenses, etc.).

3. Classification into error types (e.g. errors of agreement, articles, verb forms, etc.);

4. Statement of relative frequency of error types.
5. Identification of the areas of difficulty in the target language.

4. Morphology

Morphology is the study of the internal structure of words, and of the rules by which words are formed. The word consists of two morphemes, morph+ ology. The suffix -ology means "science of" or "branch of knowledge concerning." Thus, the meaning of morphology is "the science of (word) forms". Morphology is part of our grammatical knowledge of a language linguistic knowledge (Fromkin, and Rodman, 2011 : 81). Morphology is a branch of linguistics, it deals with the study of the internal structure of words ( Stageberg, 1981 : 83). The word morphology can be used in two ways : it refers to a sub discipline of Linguistics, but it may also be used to refer to that part of the grammar of a language that contains the rules for inflection and word-formation, that is, the word grammar"(Booij,2005 : 23). For example : the word (reopened) in the sentence (the police reopened the investigation) consists of three morphemes. They are (open, re-, and -ed ).

\subsection{Morphemes}

This study tackles morphemes in general and IMs in paticular. Morphemes are defined in different ways by different scholars. According to Stageberg (1981:.83), a short segment of language can be considered a morpheme if it meets three criteria :

a. It is a word or a part of a word which has meaning,

b. It cannot be divided into smaller units or meaningful parts without violation of its meaning and

c. It appears in different verbal environments with a relatively stable meaning. Yule (2010:67) definesthe morpheme as" a minimal unit of meaning or grammatical function ".Units of grammatical function include forms used to indicate past tense or plural, for example. In the sentence :

The police reopened the investigation.

The word reopened consists of three morphemes. One minimal unit of meaning is open, another minimal unit of meaning is re- (meaning "again") and a minimal unit of grammatical function is -ed (indicating past tense). The word (tourists) also contains three morphemes. There is one minimal unit of meaning tour, another minimal unit of meaning -ist (marking "person who does something"), and a minimal unit of grammatical function $-\mathrm{s}$ (indicating plural).Yule (ibid : 68). Morphemes are of two types, Free and bound. A free morpheme is one that can be uttered alone with meaning.For instance, in reply to "What are you going to do now?" you might answer "Eat" This is a free morpheme(Stageberg, 1981 : 85).Examples of free morphemes are cat, text, book, School, boy, girl, etc. A bound morpheme, unlike the free, cannot be uttered alone with meaning. It is always annexed to one or 
more morphemes to form a word. Examples are : ante--, ly,-s,-ed,etc.(ibid). According to Akmajian et al. (2001 : 18 ), a bound morpheme is dependent and cannot stand alone as a word and must be attached to a free morpheme to have meaning; such as, /-s/ (boys), /-er/ (taller), /-ceive/ (receive), etc. Bound morphemes fall into two categories, namely derivational morphemes and IMs. Derivational morphemes are used to make new words in the language and are often used to make words of a different grammatical category from the stem. For example, the addition of the derivational morpheme (-ness ) changes the adjective (good) to the noun (goodness).

\subsection{Definitions of Inflectional Morphemes}

The second set of bound morphemes which are our main concern, in this study, is called IMs which refer to morphemes that do not change category and do not create new lexemes, but rather change the form of lexemes so that they fit into different grammatical contexts or meanings. Grammatical contexts can include information about number (singular and plural), person (first, second, third), tense (past and present), etc (Lieber, 2009 : 88). IMs are not used to produce new words in the language, but rather to indicate aspects of the grammatical function of a word. Inflectional morphemes are used to show if a word is plural or singular, if it is past tense or not, and if it is a comparative or possessive form.

English has only eight inflectional morphemes (or "inflections") illustrated in the following sentences given by Yule (2010:69)

1 . Jim's two sisters are really different.

2. One likes to have fun and is always laughing.

3. The other liked to read as a child and has always taken things seriously.

4. One is the loudest person in the house and the other is quieter than a mouse.

Leech (2006: 55) defines inflection as "a change in the form of a word which signals a different grammatical function of the same word. The regular inflections in English are endings (suffixes) such as -ed,-(e)s or -ing added to the base form of a regular verb : want, wanted, wants, wanting". Other inflections, as leech (ibid) proceeds, take the form of a change of vowel, with or without the addition of a suffix : for instance, the irregular verb write, wrote and written are the past tense and -en participle forms. We distinguish inflectional suffixes from derivational suffixes, which derive one word from another. For example, the-s of boys is inflectional, forming the plural of the same noun. But the -ish of boyish is derivational, forming another word (an adjective) from the noun boy.(ibid) Kelly ( 1998 : p.1) cited in Adday (2011 : 10) also defines the IMs as "morphemes that are required to make a sentence grammatically correct, but, they add little meaning to the word". He means that the IMs do not change the part of speech to which it is added, but add meanings to words. In a similar way, Fromkin and Rodman (1987:7) also define IMs as those grammatical morphemes which never change the syntactic category of the word or the morpheme to which they are attached to complete words. In other words, IMs are likely to complete the different meaning of words within the same part of speech. According to this definition, IMs are subdivided into noun class, verb class and adjective class of morphemes. According to Stageberg (1981 : 92), IMs have the following features :

1. They do not change the part of speech of the word to which they are added.

Examples : sled, sleds (both nouns) cough, coughed (both verbs),cold, colder(both adjectives)

2. They come last in a word, in other words they close the word off.

For instance the verbs (play): Played, player, plays and (write) : writes, writing, write,etc.

3. They come with all stems of a given part of speech.

Examples : $\mathrm{He}$ eats, drinks, dreams,entertains,motivates.

4. They do not pile up; only one ends a word. Examples : flakes, working, higher,written.

The exception here is $\left(\mathrm{s}^{\prime}\right)$, the plural possessive of the noun, as in "the students' worries". In English, IMs are all suffixes i.e come at the end of the word; they do not change the class of a word. IMs are eight in number as listed below with examples in table (1): 
Table (1) : Types of Inflectional Morphemes

\begin{tabular}{|c|c|c|c|}
\hline SN. & $\begin{array}{c}\text { Grammatical } \\
\text { class }\end{array}$ & Inflectional morphemes & Examples \\
\hline 1 & Noun inflection & $\begin{array}{c}\text { Plural (s) inflection } \\
\text { Possessive('s)inflection }\end{array}$ & $\begin{array}{c}\text { Your children are } \\
\text { beautiful.John's book. }\end{array}$ \\
\hline 2 & Verb inflection & $\begin{array}{c}\text {-ed1 past tense } \\
\text {-S 3rd person singular } \\
\text { inflection. } \\
\text {-ing present participle } \\
\text { inflection. } \\
\text {-ed2 past participle inflection. }\end{array}$ & $\begin{array}{c}\text { He worked hard. } \\
\text { He reads well. } \\
\text { He is working all the } \\
\text { night } \\
\text { He has studied. }\end{array}$ \\
\hline 3 & $\begin{array}{l}\text { Adjective } \\
\text { inflection }\end{array}$ & $\begin{array}{l}\text {-er" comparative" inflection. } \\
\text { est" superlative" } \\
\text { inflection. }\end{array}$ & $\begin{array}{l}\text {-Ahmed is elder than } \\
\text { Ali. } \\
\text { Ahmed is my eldest } \\
\text { brother. }\end{array}$ \\
\hline
\end{tabular}

\section{Methodology}

The following sections, describe and explain the errors committed by students in their narrative essay writing. It presents the study population, material,the technique of the Data Analysis and procedures used during data collection, It explains data collection and data analysis procedures i.e. the steps which are followed during data analysis including the collection of the sample,the identification, the description, explanation and finally the evaluation of the errors i.e. causes of errors. This is to ensure the reliability of the data collected and the scientific procedure followed in this regard. The population of the present study was all third-year students at the Department of English, University of Mosul. The $\mathrm{y}$ were 100 EFL students who were randomly selected. The collected data consists of essays written by EFL third year students. As mentioned earlier, there are 100 narrative essays and100 letters which have been written by students in the mid-term examinations of the academic year 2016-2017.These essays have been collected and analyzed. The participants got the opportunity to write freely about the topics, they were asked to choose one out of two topics. The essays are mostly short and consist approximately 250-300 words. The students had no access to any books, dictionaries or any help from the teacher when writing their essays. On analyzing the essays, focus has been on the errors committed in the use of the $8 \mathrm{IMs}$. Therefore, no attention was paid to the participants' wrong spellings or the other types of errors in their essays. Corder's (1973) and Ellis's \&Barkhuizen (2005) models were adopted as both are designed to analyze learners' errors which include six stages, viz. collection of the sample,the identification of errors, the description of errors, explanation and finally the evaluation of the errors i.e. causes of errors with calculating the percentage of errors. The data of the selected sample has been collected and analyzed, and the errors are identified, described, explained and finally evaluated by the researchers, i.e. many students have committed different types of errors in their essay writing such as in spelling, grammar, structure, meaning but our main concern is to detect the errors which are committed in using the IMs without any attention to other types of errors. The following sections will explain the different types of IMs errors which are made by the students of third year.

\section{Discussion of the findings}

The main purpose of the study was to explore, analyze the IMs errors in English essays made by the third year EFL students, discover the main reasons behind their continuous occurrence and provide remedies so as to minimize committing such types of errors. To illustrate these issues, the participants' errors have been carefully studied. After setting the categories, the researcher choice is based on the eight types of IMs errors which are explained with their frequency and percentage as shown in Table (2). 
Table (2) : The frequency and percentage of the eight IMs errors

\begin{tabular}{|c|c|c|c|}
\hline SN. & $\begin{array}{c}\text { Inflectional } \\
\text { Morphemes errors }\end{array}$ & $\begin{array}{c}\text { Number of } \\
\text { occurrence }\end{array}$ & Percentage \\
\hline $\mathbf{1}$ & Past tense inflection & 309 & $35 \%$ \\
\hline $\mathbf{2}$ & Plural inflection(s) & 148 & $17 \%$ \\
\hline $\mathbf{3}$ & $\begin{array}{c}\text { Present participle } \\
\text { inflection (ing) }\end{array}$ & 123 & $14 \%$ \\
\hline $\mathbf{4}$ & Third person singular (s) & 110 & $13 \%$ \\
\hline $\mathbf{5}$ & $\begin{array}{c}\text { Past participle } \\
\text { inflection(ed2) }\end{array}$ & 100 & $7 \%$ \\
\hline $\mathbf{6}$ & Possessive ('s) & 57 & $1 \%$ \\
\hline $\mathbf{7}$ & Comparative (er) & 8 & 100 \\
\hline $\mathbf{8}$ & Superlative (est) & 9 & 864 \\
\hline $\mathbf{9}$ & Total & & $1 \%$ \\
\hline
\end{tabular}

The total number of errors found in the third-year students' essays was (864) errors (as mentioned in the above table).These errors were tabulated according to their frequency and percentage.The frequency of each error type was rank-ordered from the highest to the lowest as shown in Table (2). Table (2) shows the errors which are made by the students of the selected sample in their use of the IMs as a whole. It consists of four columns, the first one is the serial number of IMs, the second one contains the eight types of IMs, the third is the number of occurrence of errors that are found in the students' essays and the last one is the percentage of errors. The analysis of the essays revealed that the most commonly committed IMs errors were : Past tense inflection "ed1" 35\%,Plural "s" $17 \%$, Present participle inflection "ing"14\%, Third person singular "s" 13 $\%$,Past participle inflection"ed2" 12\%, possessive inflection errors $7 \%$, Comparative "er" $1 \%$ and Superlative (est) $1 \%$. First, past tense inflection errors (hence forth, ed1), shows the highest percentage of errors, that comprised $35 \%$ of the total number of errors. They are absolutely the most dominant errors. In fact, errors in (ed1) were so pervasive that all essays examined contained at least ten errors, with the majority containing many more. The past tense morpheme of English is somehow problematic and its rules are relatively complex since verbs have regular and irregular past tense forms.

Table (3) : Description of (ed1) errors with their frequency and percentage.

\begin{tabular}{|c|c|c|c|}
\hline SN. & $\begin{array}{c}\text { Description of } \\
\text { Errors }\end{array}$ & $\begin{array}{c}\text { Frequency of } \\
\text { Occurrence }\end{array}$ & Percentage \\
\hline $\mathbf{1}$ & Omission & 78 & $25 \%$ \\
\hline $\mathbf{2}$ & Addition & 160 & $52 \%$ \\
\hline
\end{tabular}




\begin{tabular}{|c|c|c|c|}
\hline $\mathbf{3}$ & Misinformation & 66 & $21 \%$ \\
\hline $\mathbf{4}$ & Misordering & 3 & $1 \%$ \\
\hline $\mathbf{5}$ & Blending & 2 & $1 \%$ \\
\hline $\mathbf{6}$ & Total & 309 errors & $35 \%$ \\
\hline
\end{tabular}

Table (3) explains the description of "ed1" errors that are found in the students' essays.The errors were explained and thoroughly examined to find out their description in terms of "omission, addition, misinformation, misordering, and blending" which is based on surface structure taxonomy that is invented by Dulay, Burt and Krashen (1982 : 150) based on the ways surface structures are altered cited in Ellis \&Barkhuizen (2005: 61) which is categorized as follows :

1. Errors of omission: when the learner has left out a word or morpheme which is needed in the context i.e. the percentage of "ed1" omission errors is $25 \%$.

2. Errors of addition: when the learner has added a word or a morpheme to another word in a wrong way.Concerning (ed1) inflection addition type of error occupied the highest rank of percentage which comprised $52 \%$ of the total number of errors.

3. Misinformation/Substitution : when the learner uses the wrong form of a morpheme or substitutes one morpheme instead of another morpheme. The misinformation errors in (ed1) is $21 \%$

4.Misordering : e.g. when the learner places a morpheme incorrectly in a grammatical construction. The percentage of the misordering errors of (ed1) inflection is 1\%. James (1998) suggests one further category to be added :

5. Blending : when the learner is uncertain of which word to use and blends two different phrases. The percentage of blending errors in $($ ed1 $)=1$.

Table (4) : Description of plural inflection (s) errors with their number and percentage.

\begin{tabular}{|c|c|c|c|}
\hline $\mathbf{S N}$. & Description of errors & $\begin{array}{c}\text { Frequency of } \\
\text { occurrence }\end{array}$ & percentage \\
\hline $\mathbf{1}$ & Omission & 67 & $45 \%$ \\
\hline $\mathbf{2}$ & Addition & 40 & $27 \%$ \\
\hline $\mathbf{3}$ & Misinformation & 41 & $28 \%$ \\
\hline $\mathbf{4}$ & Misordering & 0 & $0 \%$ \\
\hline $\mathbf{5}$ & Blending & 0 & $0 \%$ \\
\hline $\mathbf{6}$ & Total & 148 & $17 \%$ \\
\hline
\end{tabular}

Table (4) shows the description of the second dominant type of errors that is the plural inflection " $\mathrm{s}$ ", especially errors of omission type that comprises the highest percentage of errors is $45 \%$ of the total percentage of plural "s" errors that comprised $17 \%$.The errors of misinformation form $28 \%$ which is the second dominant type of errors.The addition type comprises $27 \%$ and finally the last two types of errors are the misordering type and blending type ;they comprise $0 \%$ of the total number of errors which shows the percentage of the five descriptions of the plural "s" errors.

The most prevalent errors were mainly related to the present participle inflection "ing" errors. It was the third dominant type that comprised $14 \%$ of the total 
number of errors as shown in Table (5).

Table (5) : Description of present participle inflection (ing) errors with their frequency and percentage.

\begin{tabular}{|c|c|c|c|}
\hline SN. & Description of errors & $\begin{array}{c}\text { Number of } \\
\text { occurrence }\end{array}$ & percentage \\
\hline $\mathbf{1}$ & Omission & 57 & $46 \%$ \\
\hline $\mathbf{2}$ & Addition & 37 & $30 \%$ \\
\hline $\mathbf{3}$ & Misinformation & 28 & $23 \%$ \\
\hline $\mathbf{4}$ & Misordering & 0 & $0 \%$ \\
\hline $\mathbf{5}$ & Blending & 1 & $1 \%$ \\
\hline $\mathbf{6}$ & Total & 123 & $14 \%$ \\
\hline
\end{tabular}

Third person singular "s" inflection errors came fourth in ranking. They comprised $13 \%$ of the total number of errors. The omission type of errors occupies the highest rank of percentage is $70 \%$. In other words, many students tend to omit the third person singular " $\mathrm{s}$ " morpheme that leads to a lack of concord between the subject and the verb. another type of errors is the omission ones which form $26 \%$, followed by misinformation $2 \%$, misordering $0 \%$ and blending $2 \%$. These are shown in Table (6) which illustrates the description, frequency and percentage of third person singular errors.

Table (6) : Description of third person singular inflection (s) errors with their frequency and percentage

\begin{tabular}{|c|c|c|c|}
\hline SN. & Description of errors & $\begin{array}{c}\text { Frequency of } \\
\text { occurrence }\end{array}$ & percentage \\
\hline $\mathbf{1}$ & Omission & 77 & $70 \%$ \\
\hline $\mathbf{2}$ & Addition & 29 & $26 \%$ \\
\hline $\mathbf{3}$ & Misinformation & 2 & $2 \%$ \\
\hline $\mathbf{4}$ & Misordering & 0 & $0 \%$ \\
\hline $\mathbf{5}$ & Blending & 2 & $2 \%$ \\
\hline $\mathbf{6}$ & Total & 110 & $13 \%$ \\
\hline
\end{tabular}

The fifth type of error was the Past participle "ed2"inflection errors, which formed $12 \%$ of the total 
number of errors. The highest percentage was for the misinformation type of errors that comprised $41 \%$, errors of omission $30 \%$, errors of addition $25 \%$, errors of blending $4 \%$, and finally errors of misordering $0 \%$.
See Table (7) for the description of errors with their frequency and percentage :

Table (7) : Description of past participle inflection $\left(\mathrm{ed}_{2}\right)$ errors with their frequency and percentage

\begin{tabular}{|c|c|c|c|}
\hline SN. & Description of errors & $\begin{array}{c}\text { Frequency of } \\
\text { occurrence }\end{array}$ & percentage \\
\hline $\mathbf{1}$ & Omission & 30 & $30 \%$ \\
\hline $\mathbf{2}$ & Addition & 25 & $25 \%$ \\
\hline $\mathbf{3}$ & Misinformation & 41 & $41 \%$ \\
\hline $\mathbf{4}$ & Misordering & 0 & $0 \%$ \\
\hline $\mathbf{5}$ & Blending & 4 & $4 \%$ \\
\hline $\mathbf{6}$ & Total & $\mathbf{1 0 0}$ & $\mathbf{1 2} \%$ \\
\hline
\end{tabular}

The sixth type of errors was Possessive ('s) inflection errors. This type comprised $7 \%$ of the total percentage of errors. One can state that the major cause of these errors may be due to the omission of the possessive (s) with the apostrophe from words which refers to possession that comprised $81 \%$. Furthermore, the percentage of the addition and misinformation types of errors waas $7 \%$, errors of misordering $5 \%$. The lowest percentage was for the blending types of errors $0 \%$. Consider Table 8 for the frequency and percentage of errors.

Table (8) : Description of possessive inflection ('s) errors with their frequency and percentage

\begin{tabular}{|c|c|c|c|}
\hline SN. & Description of errors & $\begin{array}{c}\text { Frequency of } \\
\text { occurrence }\end{array}$ & percentage \\
\hline $\mathbf{1}$ & Omission & 46 & $81 \%$ \\
\hline $\mathbf{2}$ & Addition & 4 & $7 \%$ \\
\hline $\mathbf{3}$ & Misinformation & 4 & $7 \%$ \\
\hline $\mathbf{4}$ & Misordering & 3 & $5 \%$ \\
\hline $\mathbf{5}$ & Blending & 0 & $0 \%$ \\
\hline
\end{tabular}




\begin{tabular}{|c|c|c|c|}
\hline $\mathbf{6}$ & Total & 57 & $7 \%$ \\
\hline
\end{tabular}

The last two types of IMs errors were comparative and adjective form. They comprised $1 \%$ of the total, as superlative inflection errors that are mainly related to shown in Tables (9) and (10) respectively:

Table (9) : Description of comparative inflection (er) errors with their frequency and percentage

\begin{tabular}{|c|c|c|c|}
\hline SN. & Description of errors & $\begin{array}{c}\text { Frequency of } \\
\text { occurrence }\end{array}$ & percentage \\
\hline $\mathbf{1}$ & Omission & 3 & $37.5 \%$ \\
\hline $\mathbf{2}$ & Addition & 1 & $12.5 \%$ \\
\hline $\mathbf{3}$ & Misinformation & 4 & $50 \%$ \\
\hline $\mathbf{4}$ & Misordering & 0 & $0 \%$ \\
\hline $\mathbf{5}$ & Blending & 0 & $0 \%$ \\
\hline $\mathbf{6}$ & Total & $\mathbf{8}$ & $\mathbf{1} \%$ \\
\hline
\end{tabular}

Table (9) explains the errors which are made by students in using comparative morpheme (er) with their description, frequency and percentage.The highest percentage of errors is that of the misinformation type since the student has wrongly used the morpheme (er) that comprised $50 \%$. It is followed by omission type $37.5 \%$, addition $12.5 \%$. Finally, the misordering and blending types of errors have the lowest percentages, namely $0 \%$ out of the total number of errors.

Table (10) : Description of superlative inflection (est)errors with their frequency and percentage

\begin{tabular}{|c|c|c|c|}
\hline SN. & Description of errors & $\begin{array}{c}\text { Frequency of } \\
\text { occurrence }\end{array}$ & percentage \\
\hline $\mathbf{1}$ & Omission & 3 & $33 \%$ \\
\hline $\mathbf{2}$ & Addition & 4 & $45 \%$ \\
\hline $\mathbf{3}$ & Misinformation & 2 & $22 \%$ \\
\hline $\mathbf{4}$ & Misordering & 0 & $0 \%$ \\
\hline $\mathbf{5}$ & Blending & 0 & $0 \%$ \\
\hline
\end{tabular}




\begin{tabular}{|l|l|l|l|}
\hline 6 & Total & 9 & $1 \%$ \\
\hline
\end{tabular}

Table (10) summarizes the description of (est) morpheme errors with their frequencies and percentages. The addition type of errors has got the highest percentage $45 \%$, followed by omission type $33 \%$, misinformation type $22 \%$ and the finally $0 \%$ for the misordering and blending types of errors.

\section{Conclusion}

The study aimed at identifying, describing, explaining, and evaluating the type of IMs errors made by EFL Students when writing essays in the English Department students' essays and the sources of these errors. As a result, different types of errors were found in their essays. These were limited to eight major types of errors, namely past tense inflection, plural inflection, present participle inflection, third person singular inflection, possessive inflection, past participle inflection, comparative inflection and superlative inflections. Based on the research findings and discussions, the researcher draws a conclusion related to the number of errors, the mastery of third year students in grammar especially in using IMs was low, i.e. the types of errors in the use of eight English IMs show that the past inflection error is in the first rank (309 or 35\%), then it is followed by plural inflection error in the second rank (148 or $17 \%$ ), in the third rank is present participle inflection error (123 or 14\%), in the fourth rank is third person singular inflection error (110 or $13 \%)$, past participle inflection error in the fifth rank (100 or $12 \%)$, the possessive inflection errors is in the sixth rank ( 57 or $7 \%$ ) and the last two inflections are comparative (er) and superlative (est) errors whose number is $(8,9)$ or $(1 \%)$ respectively of the total number of errors found of the students' writing. This means that third year students of English Department face problems and are weak in applying and understanding English morphology at large and English IMs in particular. The results of study showthat the highest percentage of error types is past tense inflection error and the lowest percentage of error types is comparative and superlative inflection error together. It can thus be concluded that EFL university students still have a long way to go to be able to write satisfactory essays in English. The way they composed their essays clearly shows their weak understanding of the basic elements of English grammar. This is on one hand. On the other hand, teachers should vary their teaching methods in order to facilitate and enable their students to write competently. Although EFL third-year students have been taught and trained to construct an effective accurate essay, most of them failed to do so due to insufficient experience and practice, inadequate grammatical and structural knowledge, insufficient linguistic experience, ignorance of English grammatical rules, inadequacy of the textbook used, test anxiety, overgeneralization of grammatical rules, concentration on content and grammar rather than form, etc. Also, there were the problems of the mother tongue interference i.e. negative transfer, and incomplete learning of essay writing rules and conventions which should not be forgotten. Accordingly, much attention should be paid to the adaptation and modulation of the course according to students' needs so as to surmount most of the shortcomings of the course, remedy the problems and come up with a good teaching program.

\section{References}

1. AbiSamra, N. (2003). An Analysis of Errors in Arabic Speakers' English Writings. Beirut : American University of Beirut Press.

2. Booij, G. (2005).The Grammar of Words, Oxford : Oxford University Press.

3. Brown, H. (2000). Principles of Language Learning and Teaching. Longman : San Fransisco State University,

4.Corder, S. (1973).Introducing Applied Linguistics. Middlesex : Penguin Books.

5. Corder, S. P. (1974). Error Analysis. In J. P. B. Allen and S. Pit Corder

6. (eds.) Techniques in Applied Linguistics (The Edinburgh Course in Applied Linguistics : 3), London : Oxford University Press (Language and Language Learning).

7.Crystal, D.(2008). A Dictionary of Linguistics and Phonetics, 6th ed. London : Longmans.

8. Dulay et al. (1982). Language Two. New York : Oxford University Press.

9. Ellis, R. and, Barkhuizen, G. (2005). Analysing Learner Language. Oxford: Oxford University Press.

10. Fromkin, V., Rodman, R. and Hyams, N. (1987). An Introduction to Language. Australia : ThomsonWadsworth.

11. Keshavarz, M. (1999. 2003). Contrastive Analysis and Error Analysis (2nd and $6^{\text {th }}$ eds.). Tehran : Rahnama Publications.

12. Leech, J. (2006 ), A Glossary of English Grammar. Edinburgh : Edinburgh University Press Ltd.

13. Lieber, R. (2009). Introducing Morphology. New York : Prentice-Hall Inc.

14. Stageberg, N. C. (1981).An Introductory English Grammar ( $4^{\text {the }}$ d). New York : Holt, Rinehart and Winston.

15. Yule, G. (2010). The Study of Language. (4th ed.) Cambridge : Cambridge University Press. 